\title{
Alcohol and radiographs in the accident and emergency department
}

\author{
P A Rust, I J Hunt, D N Wallis, A Jowett, G Rottenberg
}

\begin{abstract}
Objective-To investigate the contribution of alcohol ingestion to the radiological workload of an inner city accident and emergency (A\&E) department.

Methods-A prospective survey of patients presenting to $A \& E$ who required radiographs was performed over a seven day period. The $A \& E$ clinician questioned patients about alcohol intake during the six hours before the onset of the presenting complaint or injury, and made an objective assessment of signs of alcohol ingestion or intoxication. An assessment was made also of the relative contribution of alcohol as a cause of patients' injuries. Results-A total of 419 patients who had radiography fulfilled the inclusion criteria, and a questionnaire was completed for $351(84 \%)$. Forty (11\%) of 351 were found to have ingested alcohol. Thirty five $(87 \%)$ of 40 patients who had ingested alcohol were radiographed for trauma, as compared with 171 (55\%) of the 311 who had not $(p<0.001)$. Alcohol was considered to have been causative of injury in $30 \%$ and a contributory factor in an additional $58 \%$. Radiographs of the skull, face and jaw accounted for 18 (33\%) of 55 radiographs from trauma patients who had ingested alcohol compared with $20(9 \%)$ of 212 radiographs from those who had not $(\mathbf{p}<0.001)$. There was no significant difference in the proportion of abnormal radiographs between these two groups $(27 \%$ of radiographs from trauma patients who had ingested alcohol compared with $23 \%$ of radiographs from those who had not, p>0.2).
\end{abstract}

Accident an

Department, Guy's

and St Thomas's NHS

Trust, London, UK

P A Rust

I J Hunt

$\mathrm{D} \mathrm{N}$ Wallis

A Jowett

Department of

Radiology, Guy's and

St Thomas's NHS

Trust

G Rottenberg

Correspondence to: Miss Rust, Department of Biomedical Engineering,

Royal National Orthopaedic Hospital, Brockley Hill, Stanmore HA7 4LP, UK (p.rust@ucl.ac.uk)

Accepted for publication 15 March 2001
Conclusion-Patients with alcohol related injuries requiring radiography have a significant impact on the radiological workload of an A\&E department, although the prevalence of alcohol ingestion detected in this study was less than expected from previous studies.

(Emerg Med f 2001;18:460-461)

Keywords: alcohol; radiography; trauma

Alcohol misuse is associated with an increased incidence and severity of injury in patients presenting to accident and emergency (A\&E), whether attributable to accident or assault. ${ }^{12}$ This has prompted the suggestion that these patients should be targeted for intervention to reduce alcohol misuse. ${ }^{3-5}$ We investigated the contribution of alcohol ingestion to the radiological workload of an A\&E department. We
Table 1 The questionnaire used in alcohol and

radiographs study, and number of positive responses to each question

\begin{tabular}{ll}
\hline Question & $\begin{array}{l}\text { Number of } \\
\text { positive } \\
\text { responses }\end{array}$ \\
\hline Patient admits to having drunk alcohol within & \\
$\quad 6$ hours of onset of complaint/injury? & 34 \\
Breath smells of alcohol? & 22 \\
Patient appears intoxicated? & 15 \\
Alcohol considered & 12 \\
$\quad$ Causative? & 23 \\
Contributory? & 5 \\
Coincidental? &
\end{tabular}

The total number of patients from whom positive responses were obtained was 40 .

found no other research on this subject on a Medline search.

Methods

We performed a prospective survey of adults who presented to the A\&E department of an inner city teaching hospital during a one week period and required plain radiographs. We excluded patients under the age of 16 , complex radiological investigations (including computed tomography and contrast studies), and radiographs requested by clinicians from outside the A\&E department. Doctors recorded details of patients' alcohol ingestion on a simple questionnaire (table 1 ) before requesting radiographs. This assessment comprised direct patient questioning about alcohol intake during the six hours before the onset of the presenting complaint or injury, and brief clinical examination for signs of alcohol ingestion (smell of alcohol on the patient's breath) and signs of intoxication (such as dysarthria, incoordination). The $\mathrm{A} \& \mathrm{E}$ clinician also made a judgement based on the history of alcohol ingestion, degree of intoxication and circumstances of injury, whether alcohol ingestion was causative of, contributory or coincidental to injury.

We used $\chi^{2}$ statistical tests, comparing the proportion of radiographs performed for trauma, and part of the body radiographed and proportion of abnormal radiographs among those of trauma patients who had ingested alcohol as compared with those who had not.

\section{Results}

A total of 419 patients had plain radiographs requested by $A \& E$ clinicians, resulting in 433 radiographs. A questionnaire was completed for $351(84 \%)$. Of these 351, $40(11 \%)$ admitted to alcohol ingestion or had signs of alcohol ingestion. Thirty five $(87 \%)$ who had ingested alcohol were radiographed for trauma, compared with 171 (55\%) of 311 patients who had 
Table 2 Number of radiographs by anatomical site for trauma patients who had consumed alcohol as compared with those who had not (\%)

\begin{tabular}{|c|c|c|c|}
\hline Anatomical site & $\begin{array}{l}\text { Radiographs for } \\
\text { patients with } \\
\text { alcohol }(n=55)\end{array}$ & $\begin{array}{l}\text { Radiographs for } \\
\text { patients without } \\
\text { alcohol }(n=212)\end{array}$ & $\begin{array}{l}\text { p Value } \\
\text { (comparison of } \\
\text { proportions between } \\
\text { patients with and } \\
\text { without alcohol) }\end{array}$ \\
\hline Head (skull, face, jaw) & $18(33)$ & $20(9)$ & $<0.001$ \\
\hline Spine and pelvis & $3(5)$ & $28(13)$ & $<0.2$ \\
\hline Upper limb & $15(27)$ & $82(39)$ & $<0.2$ \\
\hline Lower limb & $5(9)$ & $53(25)$ & $<0.02$ \\
\hline Soft tissue (for suspected foreign body) & $4(7)$ & $14(7)$ & $>0.5$ \\
\hline Chest & $9(16)$ & $14(7)$ & $<0.02$ \\
\hline Abdomen & $1(2)$ & $1(<1)$ & $<0.5$ \\
\hline Total number of radiographs & $55(100)$ & $212(100)$ & \\
\hline
\end{tabular}

not $\left(\mathrm{p}<0.001, \chi^{2}=15.4\right)$. Alcohol consumption was considered to be causative of injury in $30 \%$, contributory in $58 \%$ and coincidental in $12 \%$. The number of radiographs by anatomical site is shown in table 2. Skull, face or jaw radiographs accounted for $18(33 \%)$ of 55 radiographs from trauma patients who had ingested alcohol as compared with $20(9 \%)$ of 212 from trauma patients who had not ingested alcohol $(p<0.001)$. Fifteen $(27 \%)$ of 55 radiographs from trauma patients who had ingested alcohol were reported as abnormal, compared with $48(23 \%)$ of 212 from those who had not $(p>0.2)$.

\section{Discussion}

Of all patients radiographed during the study period $11 \%$ gave a history of recent alcohol consumption or were noted to have signs of alcohol ingestion or intoxication. A significantly higher percentage $(87 \% v 13 \%)$ of the alcohol group were radiographed after injury, and in most of these alcohol was considered to be either causative or contributory. There was a significantly greater proportion of skull and facial radiographs among trauma patients who had consumed alcohol, which is consistent with the increased incidence of head injuries and violent assaults among intoxicated patients. $^{2}$ It is recognised that the absolute number of radiographs of certain anatomical sites compared in table 2 , was small. There was no significant difference in the incidence of radiological abnormality in trauma patients relative to alcohol ingestion.

Our results are consistent with the finding of a previous study that prior alcohol consumption was more likely in injured as compared with non-injured emergency department patients. ${ }^{6}$ North American studies of large number of trauma patients presenting to $\mathrm{A} \& \mathrm{E}$ found $25 \%-52 \%$ had ingested alcohol. ${ }^{14}$ Our study was confined to patients who had radiographs performed, and it may be that the prevalence of alcohol ingestion among those radiographed is less than in the total population $\mathrm{A} \& \mathrm{E}$ attenders.

Use of self reported alcohol consumption and clinical examination for signs of alcohol ingestion has the advantage of simplicity, and we achieved an $84 \%$ response rate from clinicians completing our questionnaire. However, reliance on self reporting and clinical signs may be subjective, ${ }^{7}$ and lack sensitivity. ${ }^{8}$
Questionnaire screening instruments have been shown to correlate with biological alcohol markers, ${ }^{9}$ and some have been reported to be more than $80 \%$ sensitive in identifying harmful drinking or alcohol dependence in emergency department patients. ${ }^{8}$ An alternative to screening instruments is the model based on demographic and clinical data, developed by Soderstrom et al in a trauma centre setting, to identify patients likely to have a blood alcohol concentration greater than or equal to 50 $\mathrm{mg} / \mathrm{dl} .^{10}$ In a univariate analysis of an initial cohort of patients, the proportion with a blood alcohol concentration $\geqslant 50 \mathrm{mg} / \mathrm{dl}$ was significantly higher among men, white people, victims of intentional injury, and those injured at night or on a weekend day; there was also an association with age, the greatest proportion with a blood alcohol $\geqslant 50 \mathrm{mg} / \mathrm{dl}$ being among patients in their 20 s and 30s. The model developed uses a scoring system.

If our study did underestimate the prevalence of alcohol ingestion, the effect might be expected to underestimate rather than overestimate the contribution of alcohol ingestion to radiological workload.

The findings of this study suggest that alcohol ingestion by patients attending $\mathrm{A} \& \mathrm{E}$, particularly after trauma, has significant implications for emergency radiological workload. Possible reasons for this include both the association of alcohol ingestion with injury, ${ }^{1}$ and the fact that doctors may have a lower threshold for requesting radiographs for patients who are intoxicated because alcohol makes the clinical assessment of injury more difficult. Future research into the significance of alcohol ingestion for radiological workload might use one of the more sensitive screening instruments in a larger study.

Contributors

GR proposed the idea for the study; PAR, IJH and AJ collected the data and wrote the original version of the paper; DNW contributed to the design of the study and rewrote the paper.

Funding: none.

Conflicts of interest: none.

1 Blake RB, Brinker MR, Ursia CM, et al. Alcohol and drug abuse in adult patients with muscular skeletal injury. $A m \mathcal{F}$ Orthop 1997;26:461-5.

2 Wright J, Kariya A. Assault patients attending a Scottish Wright J, Kariya A. Assault patients attending a Scottish
accident and emergency department. $\mathcal{f}$ Accid Emerg Med 1998;15:23-5.

3 Yates DW, Hadfield JM, Peters K. Alcohol consumption of patients attending two Accident and Emergency departments in North-west England. F R Soc Med 1987;80:4869.

4 Dunn CW, Donovan DM, Gentilello LM. Practical guides for performing alcohol interventions in trauma centres. $\mathcal{F}$ Trauma 1997;42:299-304.

5 Smith SG, Touquet R, Wright S, et al. Detection of alcohol misusing patients in A\&E. F Accid Emerg Med 1996;13: 308-12.

6 Cherpitel CJS. Alcohol consumption and casualties: a comparison of two emergency room populations. Br F Addiction parison of two emer.

7 Gentilello LM, Villaveces A, Ries R, et al. Detection of acute alcohol intoxication and chronic alcohol dependence by trauma centre staff. $\mathcal{F}$ Trauma 1999;47:1131-9.

8 Cherpitel CJ. Screening for alcohol problems in the emergency department. Ann Emerg Med 1995;26:158-66.

9 Nilssen O, Ries RK, Rivara FP, et al. The CAGE questionnaire and the Short Michigan Alcohol Screening Test in trauma patients: comparison of their correlation with biological alcohol markers. F Trauma 1994;36:784-8.

10 Soderstrom CA, Kufera JA, Dischinger PC, et al. Predictive model to identify trauma patients with blood alcohol concentrations $>$ or $=50 \mathrm{mg} / \mathrm{dl}$. F Trauma $1997 ; 42: 67-73$. 